there are some, even if not many, cases in which such a procedure seemed effective. Meningioma

1) In 133 cases of meningioma there are at least 21 cases (16\%) of malignant type.

2) Survival for more than 5 years is very often even in cases of incomplete removal. In these cases it would be wise to make angiography after the operation to see exactly the extent of the remaining tumor.

3) In carotid angiography it is shown that feeding arteries of meningiomas are derived to greater extent from internal carotid than from external. Surgeons should be aware of such artery or arteries before attacking the tumor.

4) Preoperative attacks of convulsions often disappear or markedly decrease after operation.

Acoustic neurinoma

In our experiences extracapsular total extirpation of the tumor is accompanied neither by higher mortality nor by better neurological states soon or late after operation.

Hypophyseal adenoma

1) Even after grossly complete curettage of the tumor the upward shift of anterior cerebral artery in angiography returns usually not remarkably.

2) Grade 1 and 2 of hypothalamic extension were divided according to the changes in iodized oil ventriculography, carotid angiography and neurological states. Immediate operation mortality is highest (50\%) in grade 2 cases and lowest $(10 \%)$ in non-extension cases.

Pineal tumors

Mortality of extirpation of pineal tumors is lowest in teratomas and highest in gliomas. Therefore, preoperative differentiation of gliomas from teratomas or pinealomas is desired. In this connection some characteristic changes in iodized oil ventriculography, carotid angiography and neurological states are suggested.

\title{
H2. A Statistical Observation of Intracranial Tumors.
}

\author{
Keiji Sano \\ Dept. of Neurosurg., Univ. of Tokyo
}

This report consists of statistics on 1546 cases of intracranial tumors (neoplastic tumors: 1354, non-neoplastic tumors :192) which were experienced in our department until December, 1960 (Table 1).

Figure 1 shows age and sex distribution of 1354 cases of neoplastic tumors. There is a slight preponderance of males over females (approximately $1.3: 1$ ). Of these, cases below the age of 15 years are seen in $17 \%$, the sex ratio being also $1.3: 1$ (male : female). Age distribution of these cases divided into supra- 


\begin{tabular}{|c|c|c|c|c|c|c|c|c|c|c|c|}
\hline $\begin{array}{l}\text { Operative } \\
\text { results }\end{array}$ & $\begin{array}{l}0 \\
0 \\
0 \\
0 \\
0 \\
\overline{0} \\
+\frac{0}{0} \\
1\end{array}$ & $\begin{array}{l}0 \\
0 \\
0 \\
0 \\
0 \\
0 \\
0 \\
\stackrel{2}{+} \\
0 \\
0 \\
0 \\
0 \\
0 \\
0 \\
1 \\
0 \\
0 \\
Z\end{array}$ & 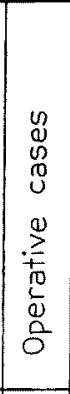 & 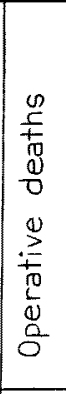 & 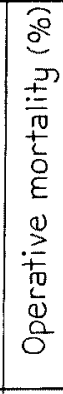 & 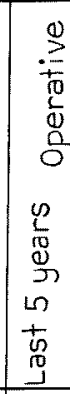 & 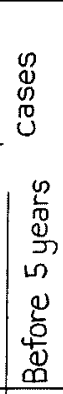 & 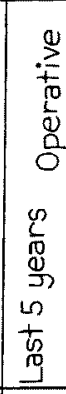 & 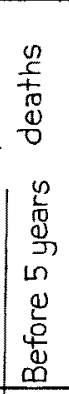 & 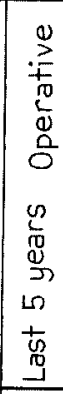 & 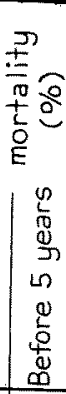 \\
\hline Medulloblastoma & 60 & 7 & 53 & 11 & 21 & 25 & 28 & 2 & 9 & 8 & 32 \\
\hline Glioblastoma & 107 & 15 & 92 & 25 & 27 & 43 & 49 & 3 & 22 & 7 & 45 \\
\hline Astroblastoma & 10 & 0 & 10 & 1 & 10 & 8 & 2 & 1 & 0 & 13 & 0 \\
\hline Astrocytoma & 119 & 13 & 106 & 10 & 9 & 63 & 43 & 4 & 6 & 6 & 14 \\
\hline Oligodendroglioma & 24 & 3 & 21 & 3 & 14 & 11 & 10 & 2 & 1 & 18 & 10 \\
\hline Spongioblastoma & 19 & 7 & 12 & 4 & 33 & 3 & 9 & 2 & 2 & 67 & 22 \\
\hline Ependymoma & 37 & 3 & 34 & 8 & 24 & 19 & 15 & 2 & 6 & 11 & 40 \\
\hline Pinealoma & 19 & 0 & 19 & 10 & 53 & 9 & 10 & 4 & 6 & 44 & 60 \\
\hline Pituicytoma & 2 & 0 & 2 & 0 & 0 & 2 & 0 & 0 & 0 & 0 & 0 \\
\hline Unclassified blastoma & 155 & 27 & 128 & 6 & 4.7 & 80 & 48 & 4 & 2 & 5 & 4.2 \\
\hline Neurinoma & 176 & 4 & 172 & 38 & 22 & 78 & 94 & 10 & 28 & 13 & 34 \\
\hline Meningioma & 201 & 6 & 195 & 33 & 17 & 89 & 106 & 10 & 23 & 11 & 22 \\
\hline Pituitary adenoma & 159 & 1 & 158 & 10 & 6 & 88 & 70 & 4 & 6 & 4.5 & 8.6 \\
\hline $\begin{array}{c}\text { Pituitary malignant } \\
\text { adenoma }\end{array}$ & 10 & 0 & 10 & 1 & 10 & 2 & 8 & 1 & 0 & 50 & 0 \\
\hline Craniopharyngioma & 97 & 4 & 93 & 11 & 12 & 53 & 40 & 6 & 5 & 11 & 12 \\
\hline $\begin{array}{c}\text { Other congenital } \\
\text { tumors }\end{array}$ & 36 & 4 & 32 & 6 & 19 & 10 & 22 & 1 & 5 & 10 & 23 \\
\hline $\begin{array}{l}\text { Papilloma of the } \\
\text { Choroid plexus }\end{array}$ & 11 & 0 & 11 & 2 & 18 & 5 & 6 & 1 & 1 & 20 & 17 \\
\hline Paraganglioma & 3 & 0 & 3 & 1 & 33 & 3 & 0 & 1 & 0 & 33 & $\angle$ \\
\hline Angiomatous tumors & 25 & 1 & 24 & 4 & 17 & 12 & 12 & 1 & 3 & 8 & 25 \\
\hline Sarcoma & 15 & 0 & 15 & 2 & 13 & 4 & 11 & 0 & 2 & 0 & 18 \\
\hline Metastatic tumors & 52 & 13 & 39 & 6 & 15 & 22 & 17 & 2 & 4 & 9 & 24 \\
\hline $\begin{array}{c}\text { Intracranially protruding } \\
\text { bony tumors }\end{array}$ & 17 & 0 & 17 & 0 & 0 & 13 & 4 & 0 & 0 & 0 & 0 \\
\hline $\begin{array}{c}\text { Aneurysm \& arteriovenous } \\
\text { aneurysm }\end{array}$ & 80 & 15 & 65 & 2 & 3 & 45 & 20 & 2 & 0 & 4.5 & 0 \\
\hline Tuberculoma & 23 & 1 & 22 & 2 & 9 & 5 & 17 & 1 & 1 & 20 & 6 \\
\hline Abscess & 31 & 6 & 25 & 7 & 28 & 6 & 19 & 0 & 7 & 0 & 37 \\
\hline Parasitic tumors & 9 & 2 & 7 & 0 & 0 & 0 & 7 & 0 & 0 & 2 & 0 \\
\hline Other granulomas & 5 & 0 & 5 & 2 & 40 & 1 & 4 & 0 & 2 & 0 & 50 \\
\hline Arachnoiditis & 22 & 1 & 21 & 1 & 5 & 13 & 8 & 0 & 1 & 0 & 13 \\
\hline Cysts & 12 & 0 & 12 & 1 & 8 & 5 & 7 & 0 & 1 & 0 & 14 \\
\hline Tuberous sclerosis & 10 & 2 & 8 & 4 & 50 & 1 & 7 & 0 & 4 & 0 & 57 \\
\hline Total & 1546 & 135 & 1411 & 211 & 15.0 & 718 & 693 & 64 & 147 & 8.9 & 21.2 \\
\hline
\end{tabular}

Table 1. Statistics on 1546 cases. 

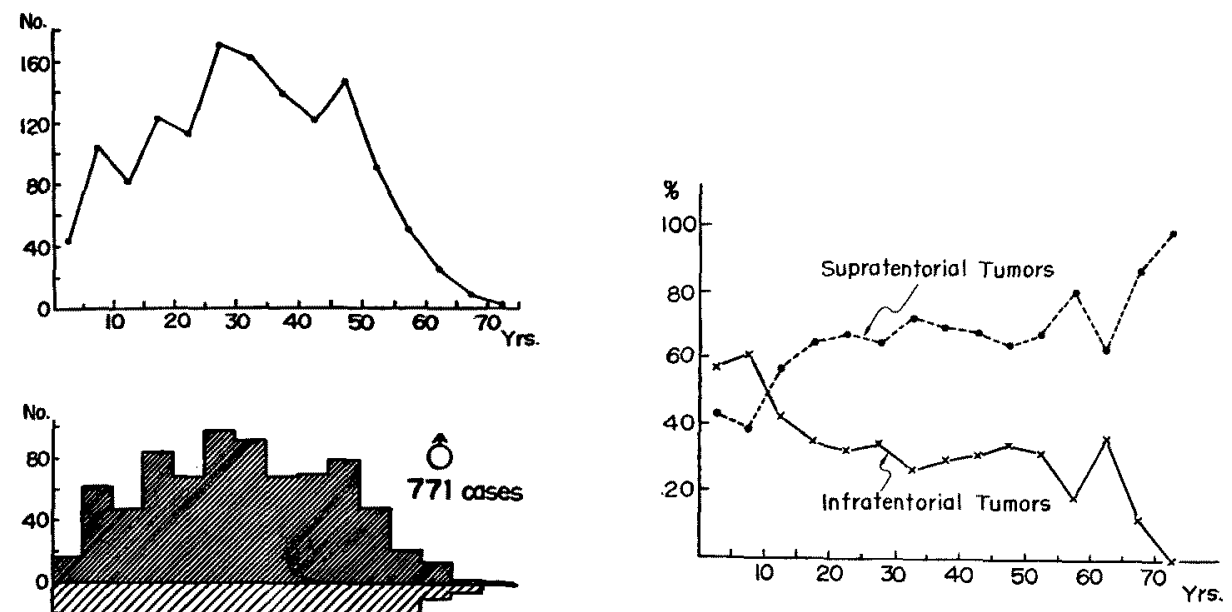

Fig. 2 Intracranial Neoplasms (1354 Cases)
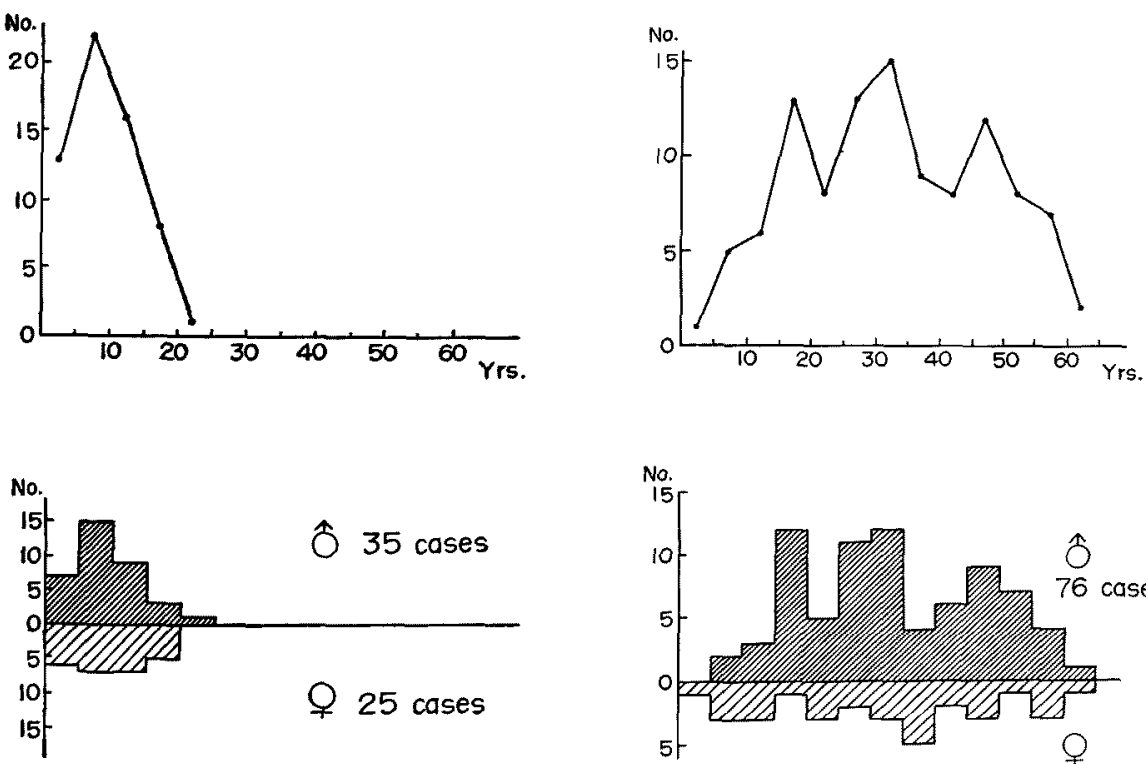

Fig. 3 Medulloblastoma (60 Cases)

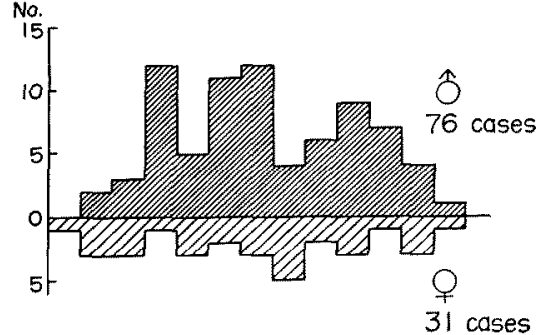

Fig. 4 Glioblastoma (107 Cases) 

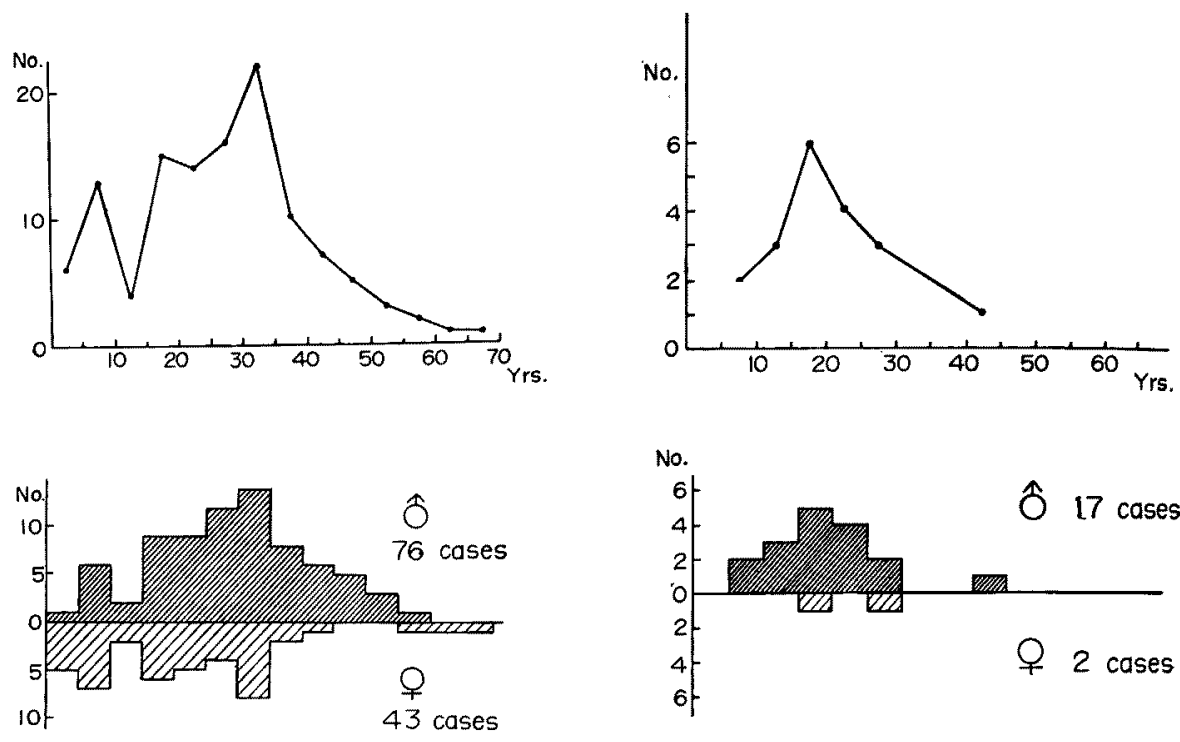

Fig. 5 Astrocytoma (119 Cases)

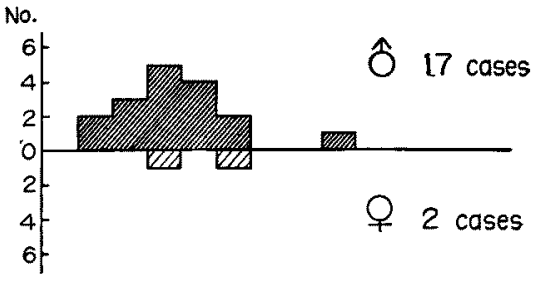

Fig. 6 Pinealoma (19 Cases)
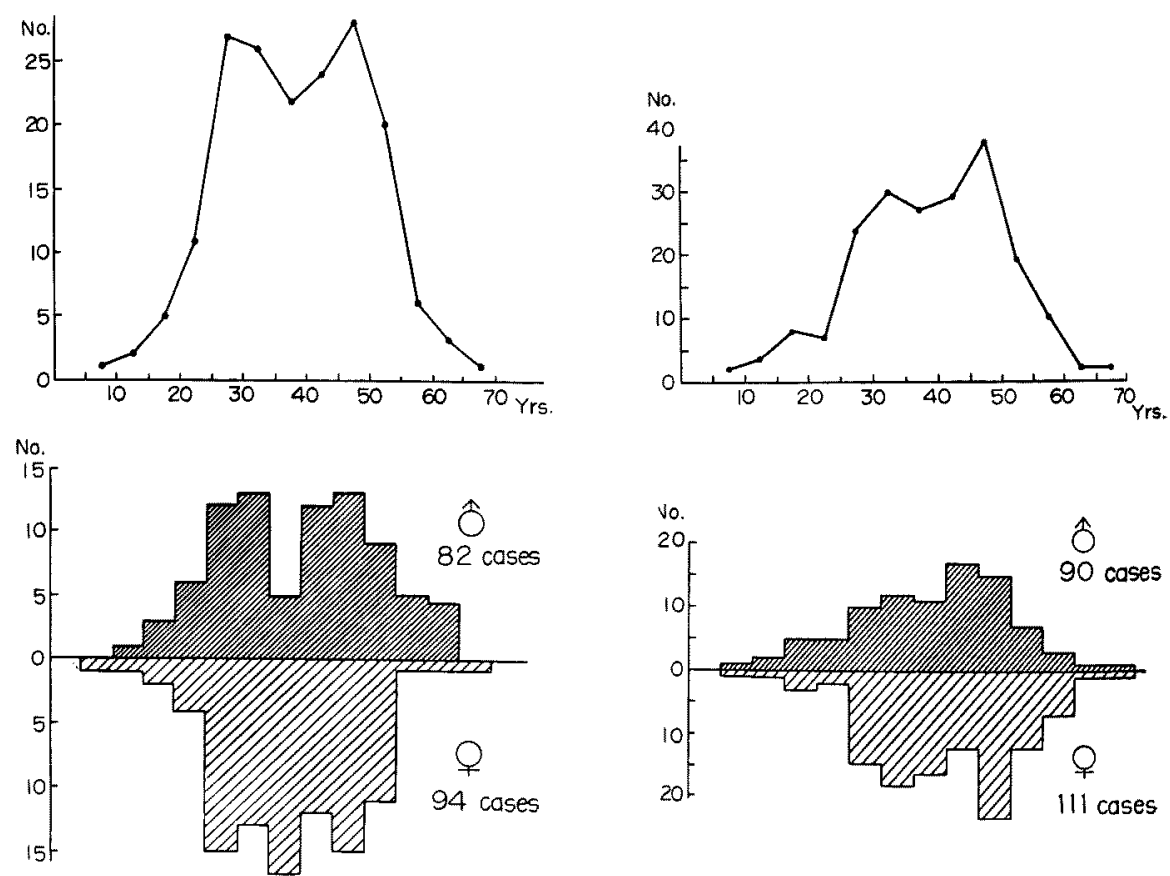

Fig. 7 Neurinoma (176 Cases)

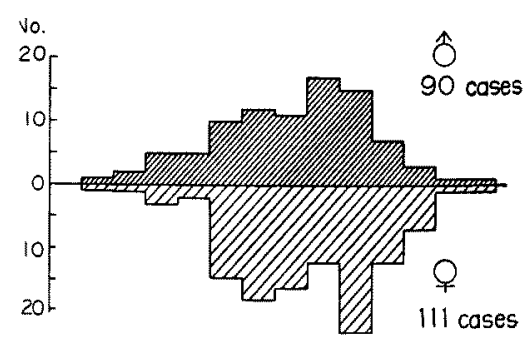

Fig. 8 Meningioma (201 Cases) 

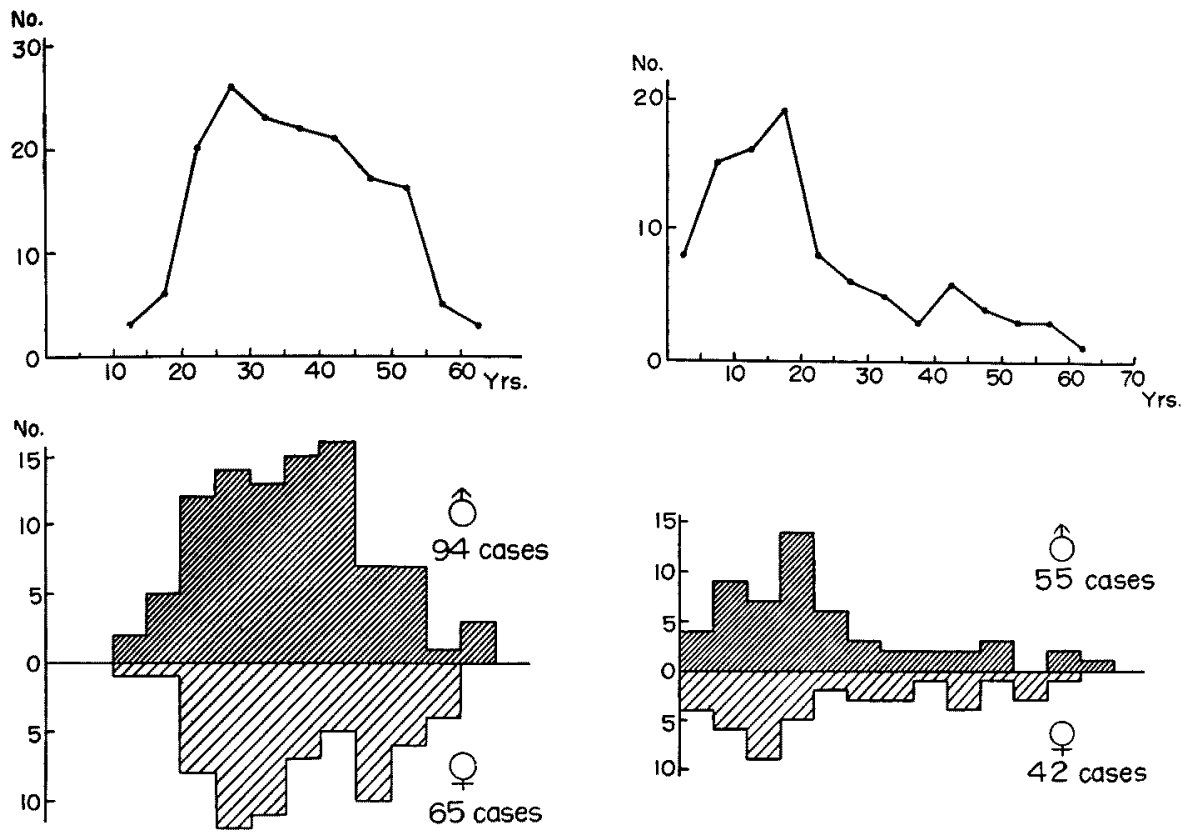

Fig. 9 Pituitary Adenoma (159 Cases)

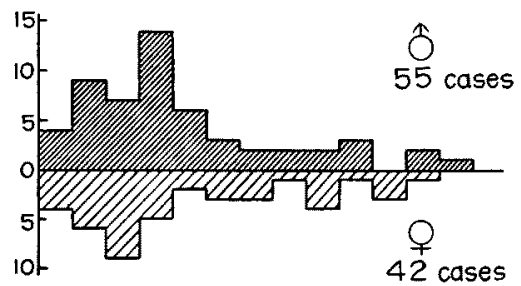

Fig. 10 Craniopharyngioma (97 Cases)
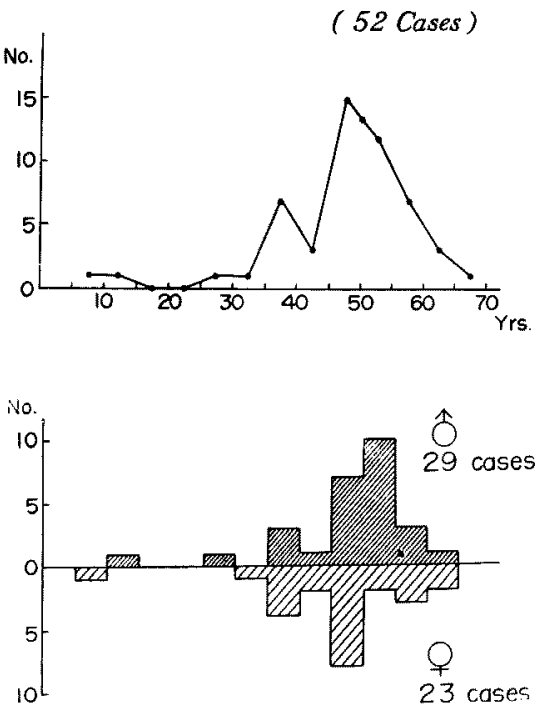

Fig. 11 Metastatic Tumors (52 Cases) 


\begin{tabular}{|l|c|c|c|c|c|}
\hline & $\begin{array}{c}\text { Our series } \\
(1961)\end{array}$ & $\begin{array}{c}\text { All Japan } \\
(1957)\end{array}$ & $\begin{array}{c}\text { Zülch } \\
(1957)\end{array}$ & $\begin{array}{c}\text { Olivecrona } \\
(1955)\end{array}$ & $\begin{array}{c}\text { Cushing } \\
(1932)\end{array}$ \\
\hline Glioma & $25.7 \%$ & $32.2 \%$ & $42.8 \%$ & $46.8 \%$ & $42.6 \%$ \\
Meningioma & 13.1 & 15.9 & 18.0 & 19.2 & 13.4 \\
Neurinoma & 11.8 & 12.1 & 7.6 & 8.0 & 8.7 \\
Pituilary adenoma & 11.0 & 11.0 & 8.0 & 8.5 & 17.8 \\
Congenital tumors & 8.6 & 9.6 & 4.8 & 2.7 & 5.6 \\
(Craniopharyngioma) & $(6.3)$ & $(7.2)$ & $(2.5)$ & $(1.7)$ & $(4.6)$ \\
Vascular tumors & 6.8 & 4.0 & 3.8 & 9.4 & 2.0 \\
Granuloma \& Abscess & 4.4 & 3.1 & 0.8 & 1.0 & 2.2 \\
Metastatic tumors & 3.3 & 4.3 & 4.0 & 3.4 & 4.2 \\
Primary sarcoma & 1.0 & 0.7 & 2.7 & - & 0.7 \\
Papilloma of choroid & 0.7 & 0.5 & 0.5 & 0.3 & 0.6 \\
Plexus & 1546 & 3312 & 6000 & 5250 & 2023 \\
\hline Total cases of tumors & 1.0 & & & & \\
\hline
\end{tabular}

Table 2. Principal intracranical tumors

and infra-tentorial tumors is shown in Figure 2. The cross-point of the curves is located slightly above the age of 10 years.

Tables 2 and 3 indicate incidence of principal tumors and glioma types in our series and others ${ }^{12)}$. The relatively low incidence of the glioma in our series is possibly due to the fact that we excluded those cases of deep subcortical tumors of which biopsy could not be done. If the latter is included, the glioma incidence becomes $36 \%$. This is still low as compared to those in European and American statistics. The granuloma and abscess are of higher incidence than those in European-American series. In the last 5 years, however, the incidence has been markedly reduced (about $1.1 \%$ ). Among gliomas pinealoma is definitely or higher incidence ( 4 or 5 times as high as those in European-American series), although we excluded all pineal tumors of which biopsy was not performed. 


\begin{tabular}{|c|c|c|c|c|}
\hline & $\begin{array}{c}\text { Our series } \\
(1961)\end{array}$ & $\begin{array}{c}\text { All Japan } \\
\text { (1957) }\end{array}$ & $\begin{array}{l}\text { Zülch } \\
\text { (1957) }\end{array}$ & $\begin{array}{c}\text { Cushing } \\
\text { (1932) }\end{array}$ \\
\hline Glioma, total & 397 & 997 & 2569 & 862 \\
\hline Neuroepithelioma & $0 \%$ & $0.1 \%$ & $0 \%$ & $0.2 \%$ \\
\hline Medulloblastoma & 15.3 & 10.7 & 8.9 & 10.0 \\
\hline Glioblastoma & 26.9 & 19.3 & 28.7 & 24.1 \\
\hline Astroblastoma & 2.5 & 2.4 & - & 4.1 \\
\hline Astrocytoma & 30.0 & 26.4 & 14.8 & 29.6 \\
\hline Oligodendroglioma & 6.1 & 6.3 & 19.1 & 3.1 \\
\hline Spongioblastoma polare & 4.8 & 4.9 & 16.3 & 3.7 \\
\hline Ependymoma & 9.3 & 12.3 & 10.1 & 2.9 \\
\hline Pinealoma & 4.8 & 9.3 & 1.0 & 1.6 \\
\hline Pituicytoma & 0.5 & - & - & - \\
\hline Ganglioneuroma & 0 & 0.3 & 1.1 & 0.4 \\
\hline Unclassified & - & 7.7 & - & 20.3 \\
\hline
\end{tabular}

Table 3. Incidence of glioma types

Figures 3-11 demonstrate age and sex distribution of principal intracranial neoplasms. Generally speaking, clinically malignant tumors are more frequently seen in males and clinically benign ones in females.

Table 4 grossly summarizes locations of intracranial tumors. Cerebral tumors, that is, supratentorial tumors except for pituitary and pineal tumors are most frequently seen (44\%). Cerebello-pontine angle tumors are of higher incidence than cerebellar tumors in our series. Figure 12 shows locations of 


\begin{tabular}{|l|c|c|c|}
\hline & Our series & Cushing & Zülch \\
\hline Cerebral & $44 \%$ & $46 \%$ & $52 \%$ \\
Pituitary & 25 & 26 & 11.8 \\
Cerebellar & 12 & 16 & 16.2 \\
Cerebellopontine angle & 15 & 10 & 9.5 \\
Brain stem & 3 & 1.1 & 7.3 \\
Skull & 1 & 0.9 & - \\
\hline
\end{tabular}

Table 4. Locations of Intracranial Tumors

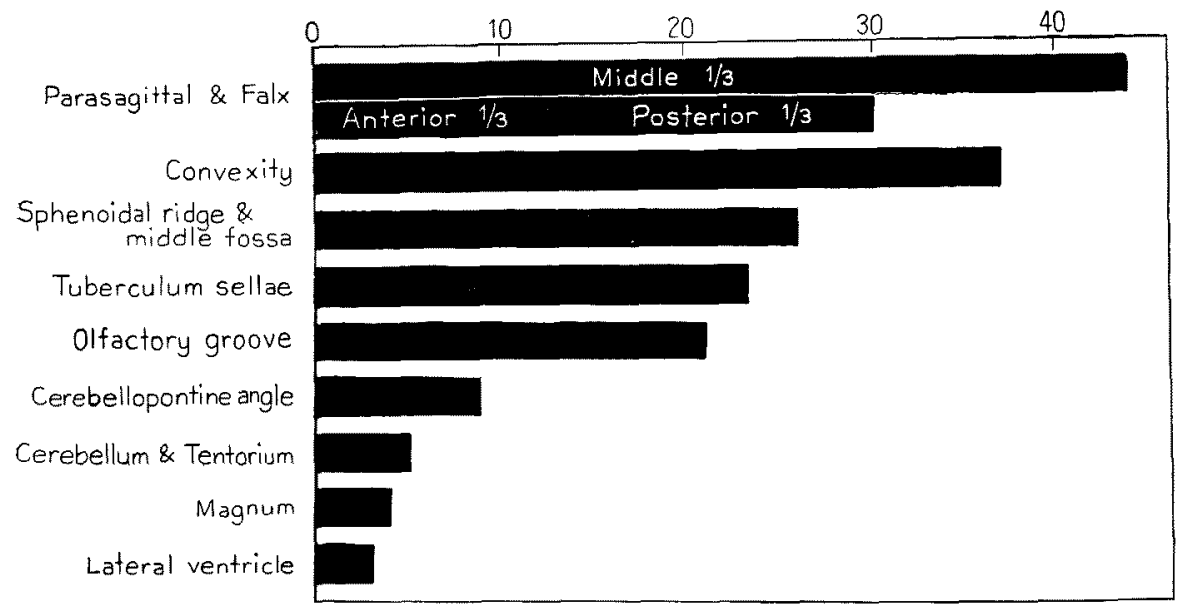

Fig. 12 Location of Meningiomas (201 Cases)

meningiomas. Parasagittal and falx meningiomas occupy about $40 \%$ of the total.

The operative mortality in 1411 operative cases is $15 \%$. That of 718 cases in the last 5 years is definitely lower $(8.9 \%)$ than that of 693 cases before 5 years $(21.2 \%)$. This remarkable decrease of mortality in the last 5 years is probably due to developments in anesthesia.

The follow-up is indicated by the survival rate. The $x$-year survival rate of the cases operated before $n$ years is shown by (cases survived $x$ years or more) $X$ $100 /$ (cases operated before $n$ years) - (the operative deaths). The lowest curve 


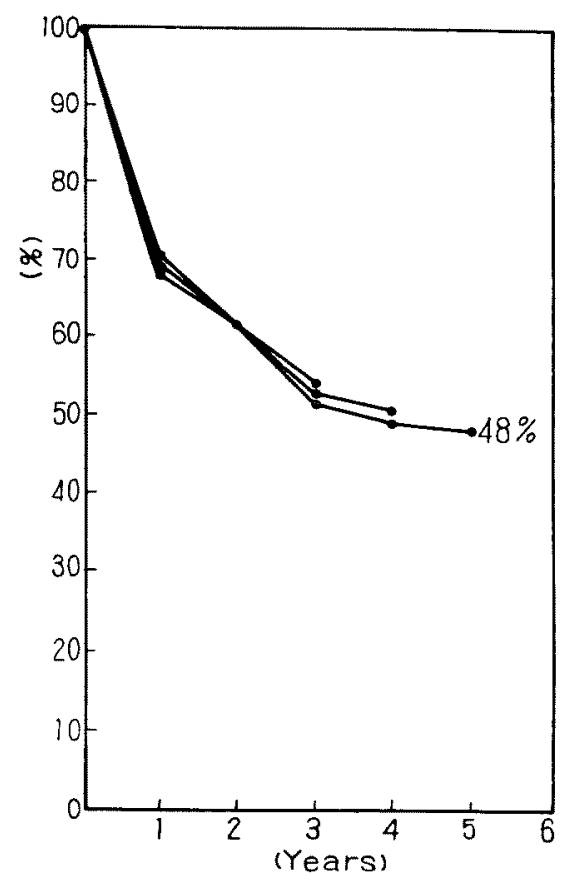

Fig. 13 Survival rate of operated cases of intracranial tumors.

in Figure 13 illustrates 1, 2, 3, 4 and 5-year survival rates of the cases operated before 5 years, the 5 -year survival rate being $48 \%$. The upper traces demonstrate chronological survival rates of the cases operated before $4,3,2$, and 1 years respectively. The traces are shifting upward every year, though to a limited extent; that is, the survival rate is gradually increasing year after year ${ }^{3)}$. This 5-year survival rate $(48 \%)$ is by far better than that of cases with stomach or breast cancers.

How these survival cases are living is an important problem. This was investigated by inquiring letters with 363 answers. According to them, 41.3\% of the survival cases are back to their former occupations, and $19.3 \%$ are capable of doing domestic works, though they are not fully satisfied with their recovery. In short, about $60 \%$ of survival cases are spending useful lives. These results are very encouraging and will be and should be improved in the nearest future by developments in surgical techniques, in radiation- and chemo-therapies.

\section{References}

1. Katsura, S., Suzuki, J. \& Wada, T.: A statistical study of brain tumors in the neurosurgical clinics in Japan. J. Neurosurg., 16:570-580, 1959.

2. Zülch, K. J.: The present state of the classification of intracranial tumors and its value for the neurosurgeon. Zbl. Neurochir., 17: 205-298, 1957.

Brain Tumors. their Biology and Pathology. New York: Springer Publ. co., 1957.

3. Shimizu, K., Sano, K., Kusama, S., Kitamura, K., Kuwabara, T., Nakamura, N., Sato, F. \& Chigasaki, H.: The follow-up studies of brain tumors (Japanese) 60th Ann. Meet. Jap. Surg. Soc. Apr. 1960. 